\title{
A Long-Term Follow-Up Investigation of Endobronchial Valves in Emphysema (the LIVE Study): Study Protocol and Six-Month Interim Analysis Results of a Prospective Five-Year Observational Study
}

\author{
Dirk Skowasch ${ }^{a} \quad$ Andreas Fertl $^{b}$ Björn Schwick ${ }^{c}$ Harald Schäfer $^{d}$ \\ Andreas Hellmann ${ }^{e}$ Felix J.F. Herth ${ }^{f}$ on behalf of the LIVE Study Investigators \\ ${ }^{a}$ Department of Internal Medicine II - Pneumology, University of Bonn, Bonn, ${ }^{b}$ Klinik für Innere Medizin/ \\ Pneumologie, Krankenhaus Martha-Maria, Munich, ' 'Lungenklinik, Medizinisches Zentrum Städteregion Aachen, \\ Würselen, ${ }^{d}$ Innere Medizin, SHG-Kliniken Völklingen, Völklingen, ${ }^{e}$ Zentrum für Pneumologie, Onkologie und \\ Schlafmedizin, Augsburg, and ${ }^{\mathrm{f} P n e u m o l o g y}$ and Critical Care Medicine, Thoraxklinik and Translational Lung \\ Research Center Heidelberg, University of Heidelberg, Heidelberg, Germany
}

\section{Key Words}

Chronic obstructive pulmonary disease - Emphysema .

Endoscopic lung volume reduction - Endobronchial valves . Interventional pulmonology

\footnotetext{
Abstract

Background: Randomized controlled trials indicate that significant lung volume reduction (ELVR) can be obtained with $Z_{\text {Zephyr }}{ }^{\circledR}$ valves by occluding the target lobe in the absence of collateral ventilation, leading to relevant functional benefits in advanced emphysema patients. Objectives: To observe the long-term effects of endobronchial valve (EBV) implantation in emphysema patients screened by Chartis assessment in the context of daily pulmonology practice. Methods: The LIVE Study is a prospective, observational, open-label, single-arm, multicenter trial conducted in Germany. 498 patients included in this interim analysis were enrolled between July 2, 2012, and September 16, 2014. The 6-month follow-up visit data were recorded for 343 patients
}

(safety population), and complete data sets were available for 321 treated patients (efficacy population) $-56.4 \%$ male, age: 64.5 years, forced expiratory volume in $1 \mathrm{~s}\left(\mathrm{FEV}_{1}\right) \%$ predicted: $31.3 \%$, residual volume (RV) $\%$ predicted: $252 \%$. Results: Efficacy results at 6 months: $\mathrm{FEV}_{1}(\mathrm{I})$ increased by $+100 \mathrm{ml}(+11.9 \%), \mathrm{RV}(\mathrm{I})$ decreased by -0.42 liter, and the COPD Assessment Test score decreased by -3.14 points (each $p<0.0001$ ). Safety outcomes: A total of 66 adverse events (AEs; with 50 serious AEs - SAEs) were reported in 55 patients (16\%) during the hospital stay for EBV placement pneumothorax (35 cases), chronic obstructive pulmonary disease (COPD) exacerbation (5 cases), and pneumonia (4 cases). During the subsequent 6-month follow-up window, 170 SAEs were recorded in 125 patients (36.4\%), predominantly COPD exacerbation (53\% of the SAEs). Conclusion: The current results of this large-scale German observational study performed in the context of daily practice further demonstrates that ELVR with Zephyr ${ }^{\circledR}$ valves is an effective and well-tolerated treatment option in advanced emphysema.

(c) 2016 S. Karger AG, Basel

\section{KARGER}

E-Mail karger@karger.com

www.karger.com/res
C 2016 S. Karger AG, Basel

$0025-7931 / 16 / 0922-0118 \$ 39.50 / 0$ 


\section{Introduction}

Emphysema is one component of chronic obstructive pulmonary disease (COPD). It is a progressive, debilitating disease characterized by irreversible destruction of alveolar tissue. The result is a reduction in elastic recoil, progressive hyperinflation and gas trapping. Patients experience chronic dyspnea, limited exercise tolerance and poor health-related quality of life [1]. COPD is the fourth most common cause of death according to the WHO [2], and will become the third leading cause of death by 2020 according to GOLD 2014 [3]. Patients with severe emphysema remain significantly disabled despite current best practices of medical care, pulmonary rehabilitation and long-term oxygen.

Whereas lung volume reduction surgery is associated with significant morbidity and mortality, i.e. a 3-month postoperative mortality rate of $5-10 \%[4,5]$, minimally invasive bronchoscopic lung volume reduction techniques through the implantation of one-way valves have now been established as a means of treating the hyperinflation of emphysema [6]. Endoscopic Zephyr ${ }^{\circledR}$ valve implantation was studied first in two randomized controlled trials (RCTs) $[7,8]$ showing significant but moderate improvements in forced expiratory volume in $1 \mathrm{~s}$ $\left(\mathrm{FEV}_{1}\right)$ and in the 6-min walk test (6-MWT) distance and highlighting the need for a method of prospectively identifying patients with low collateral ventilation (CV) who would be likely to respond to endobronchial valve (EBV) therapy. Subsequently, the prospective European multicenter Chartis Study [9] demonstrated an increased predictability of lung volume reduction after endoscopic lung volume reduction (ELVR) using the Chartis Pulmonary System, a diagnostic device designed to detect the presence of $\mathrm{CV}$ by measuring the pressure and flow in isolated lung compartments [10]. More recently, the results of two new RCTs were published: the BeLieVeR HIFi study [11] and the STELVIO Trial [12] confirmed the clinical benefit of ELVR after considering CV. While the BeLieVeR-HIFi study used visual assessment of fissure integrity to select patients, Chartis measurements confirmed the diagnostic value of the system in identifying potential responders. The STELVIO trial selected patients using the Chartis system.

While clinical evidence from RCTs, controlled trials and case series [13-23] demonstrates that by achieving lobar occlusion in the absence of $\mathrm{CV}$, significant lung volume reduction can be obtained with associated significant clinical responses in severe emphysema patients, the efficacy/safety profile of the Zephyr ${ }^{\circledR}$ valve has not been reported in a large-scale observational study under conditions of daily clinical practice. We now report the study design and interim clinical results of the LIVE Study which was designed to gather safety and effectiveness data on EBV therapy in the real-world setting.

\section{Methods}

The LIVE Study was designed as a prospective, observational, open-label, single-arm, multicenter German cohort study (clinicaltrials.gov NCT01580215) to observe in conditions of daily clinical practice the long-term effects of Zephyr ${ }^{\circledR}$ EBV placement in emphysema patients first assessed by Chartis. The primary objective is to evaluate pulmonary function at 2 years following EBV placement. The secondary objective is to evaluate pulmonary function, health-related quality of life and survival at intervals over the 5 years following EBV placement.

\section{Study Design}

Patients were recruited from pulmonology centers that referred patients with emphysema to a treatment center (TC) for potential EBV treatment. Referral centers (RCs) are qualified physicians with experience in managing GOLD stage 3 and 4 COPD patients, and TCs are interventional pulmonology centers with experience in the use of the Chartis System and the placement of Zephyr ${ }^{\circledR}$ EBVs. Two hundred RCs were targeted with an initial recruitment goal of 2,000 patients. Patients were enrolled between July 2012 and July 2015.

\section{Study Participants}

The decision to refer a patient was based on the judgment of the RC and in accordance with local clinical practice. The patient consent and baseline data were collected by the RCs. The TCs performed additional assessments; if the TC considered the patient unsuitable for EBV treatment, the patient was excluded from the study. If the patient was considered a suitable candidate, the TC treated the patient with EBVs according to the local protocol, having first confirmed the absence of CV using the Chartis Pulmonary Assessment System.

The criteria for inclusion in the study were: 18 years and older; signed written informed consent; $\mathrm{FEV}_{1}>15$ and $<45 \%$ of predicted; residual volume $>180 \%$ of predicted, and diagnosis of emphysema with CT evidence of hyperinflation. Patients with active pulmonary infection were excluded from the study. Follow-up assessments occurred at 3, 6, 9, and 12 months from first EBV implantation, and then annually up to a maximum of 5 years. All patients remained in the study regardless of any other care or treatment (e.g. lung volume reduction surgery) they may receive in the follow-up period. Patients were withdrawn from the study if consent was revoked or if they did not return to the site for their follow-up visits within 6 months of their scheduled visit.

This study is being performed in accordance with the Declaration of Helsinki. The study was approved first by the Heidelberg Ethics Committee and later by 24 Ethics Committees local to the RCs and TCs. 


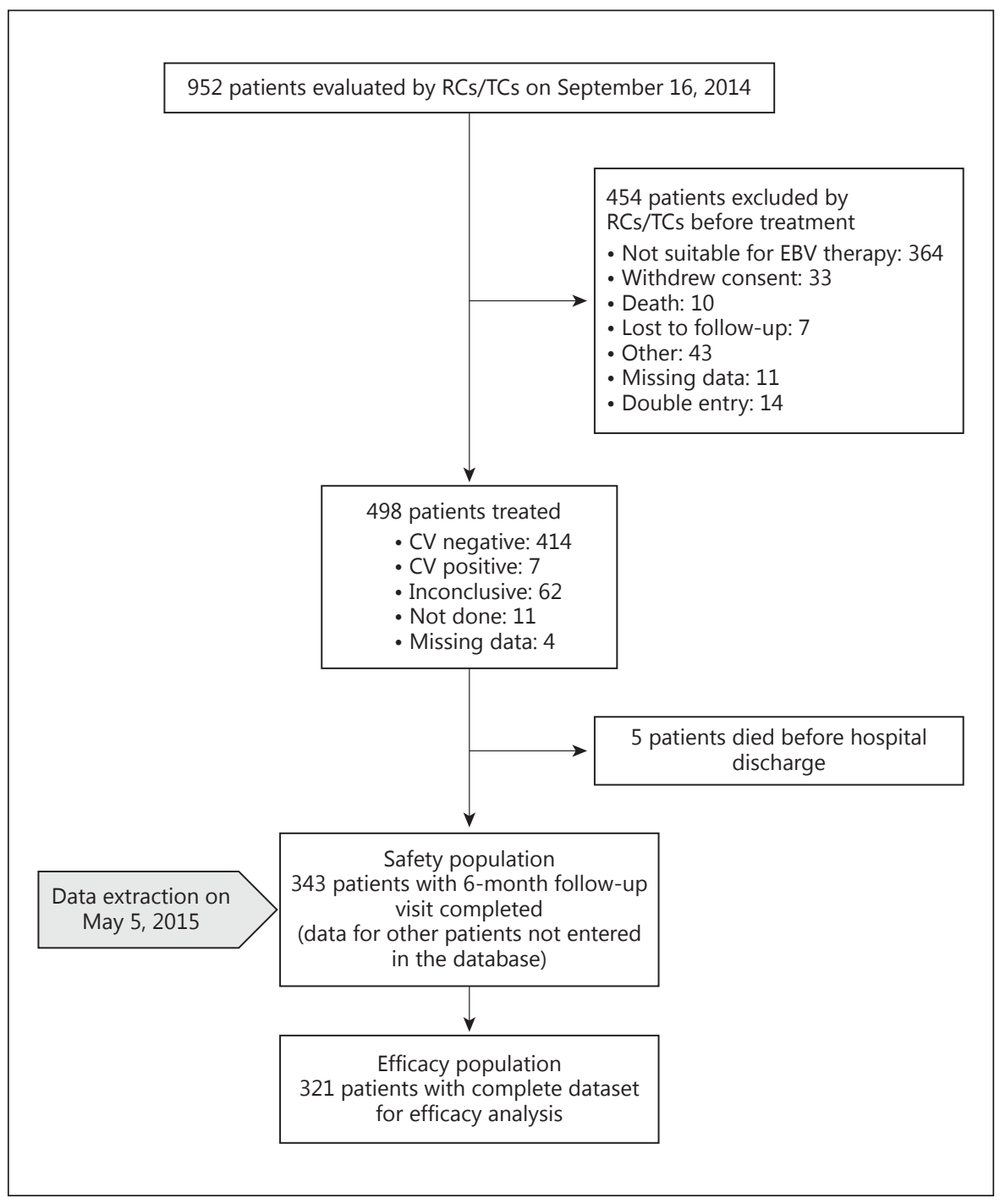

Fig. 1. Patient disposition flow chart.

Primary and Secondary Endpoints

The primary efficacy endpoint is the relative (percentage) change in $\mathrm{FEV}_{1}$ from baseline to 2 years.

Secondary endpoints include the relative (percentage) change in $\mathrm{FEV}_{1}$, absolute and relative change in dyspnea, absolute and relative change in health-related quality of life, all from baseline to each follow-up visit over the 5 -year period, and survival at 5 years. All adverse events (AEs) occurring in the procedural window and all serious AEs (SAEs) that occurred during the subsequent followup were used to assess safety.

\section{Data Sources/Measurements}

$\mathrm{FEV}_{1}$ and all pulmonary function tests, and other clinical investigations were performed according to the normal clinical practice of the local RC and TC. Dyspnea was assessed using the Modified Medical Research Council Dyspnea Score (mMRC) which comprises of 5 statements that describe almost the entire range of respiratory disability from none (grade 1 ) to almost complete in- capacity (grade 5). The mMRC can be self-administered or administered by an interviewer with the statements framed as questions. Health-related quality of life was assessed using the COPD Assessment Test (CAT), a validated eight-question tool developed to help patients and clinicians assess and quantify the impact of COPD. CAT scores are strongly correlated with scores of the St. George's Respiratory Questionnaire.

\section{Study Size}

The study sample size estimation was based on the results of a prior clinical investigation [9]. The objective performance criterion will be the $95 \% \mathrm{CI}$ of the relative mean change of $\mathrm{FEV}_{1}$ from baseline to the 2-year follow-up visit. A sample size of 2,000 patients was calculated to produce a $95 \%$ CI not containing zero, assuming a mean \pm SD change of $16 \pm 22 \%$ with a power $>99 \%$. A mortality rate of $50 \%$ during the 2 -year observation time of the primary endpoint would achieve the same power. 
Table 1. Demographic characteristics at baseline

\begin{tabular}{lcl}
\hline & Population $(\mathrm{n}=321)$ & Unknown \\
\hline Gender, m/f & $181 / 140$ & - \\
Age, years & $64.5 \pm 7.7$ & - \\
Weight, kg & $68.2 \pm 16.2$ & - \\
Height, cm & $169.4 \pm 8.8$ & - \\
BMI & $23.6 \pm 4.8$ & - \\
$\alpha_{1}$-Antitrypsin deficiency & $17(5)$ & $90(28)$ \\
\hline
\end{tabular}

Data are presented as mean $\pm \mathrm{SD}$ or $\mathrm{n}(\%)$.

Table 2. COPD-related baseline characteristics parameters

\begin{tabular}{lcc}
\hline & $\begin{array}{l}\text { Population } \\
(\mathrm{n}=321)\end{array}$ & Unknown \\
& & \\
\hline $\mathrm{FEV}_{1}$ & $0.85 \pm 0.3$ & - \\
$\quad$ Liters & $31.3 \pm 8.4$ & - \\
\% predicted & & \\
$\mathrm{RV}$ & $5.69 \pm 1.3$ & 1 \\
$\quad$ Liters & $252 \pm 54$ & 1 \\
$\quad \%$ predicted & & \\
FVC & $1.95 \pm 0.75$ & 2 \\
$\quad 56 \pm 15.4$ & 2 \\
$\quad$ Liters & $3.0 \pm 0.82$ & 4 \\
mMRC dyspnea score, points & $24.53 \pm 6.7$ & 10 \\
CAT score, points & & \\
Prior pulmonary rehabilitation & $89(29)$ & 64 \\
$\quad$ program & $170(53)$ & 2 \\
Oxygen therapy &
\end{tabular}

Data are presented as mean \pm SD or $\mathrm{n}(\%)$.

Bias

The large number of planned RCs (200) was chosen to reduce potential bias that could result from local variations in the management of patients with emphysema. In order to ensure that the study population is as representative as possible across Germany, each site was to enroll a minimum of 5 patients.

\section{Adverse Events}

All AEs, defined as any untoward medical occurrence (side effect/complication) in a patient, were collected from the time the patient received EBVs to the time the patient was discharged from the hospital. After discharge, the reporting of SAEs was in accordance with the usual vigilance system for a product in commercial use.

\section{Statistical Methods}

Descriptive statistics are provided for baseline demographic and clinical characteristics for continuous variables; categorical variables are summarized using frequency tabulations. The analysis of the primary endpoint is descriptive and includes the 95\% CI which is calculated under the assumption that the data follow a normal distribution. For all the secondary endpoints, descriptive statistics, actual differences, and percentage differences from baseline of $\mathrm{FEV}_{1}, \mathrm{mMRC}$ scores and CAT scores over time are analyzed. For all parameters, the values between baseline and the 6-month visit are compared using a paired t test.

\section{Results}

\section{Participating Sites}

A total of 144 sites are involved in this German observational study: 93 sites acting as RCs (see Appendix), and 51 sites acting as TCs (see Acknowledgements), or as both referral and treatment centers. Thus, the vast majority of the German academic interventional pulmonology centers are participating in the study, so that the clinical outcomes of this registry are representative of the emphysema patients' management in the German healthcare system.

\section{Study Population}

A total of 952 patients were evaluated between July 2, 2012, and September 16, 2014, by the participating sites, with 861 (90.4\%) referred to a TC. After the required repeat clinical workup and the Chartis assessment, a total of 454 of 952 patients were judged unsuitable for ELVR with EBVs, resulting in 498 patients being treated, with a mean number of four valves per patient. Among the 498 treated patients, 5 died during the initial hospital stay. Patient disposition is shown in figure 1 . The interim analysis in this publication is based on database extraction performed on May 5, 2015. At this time, individual data including the 6-month follow-up visit data had been entered for 343 patients (safety population). Complete patient data sets for efficacy analysis are currently available for $321 \mathrm{pa}-$ tients (efficacy population). The interim demographic and COPD-related baseline characteristics of the enrolled population are shown in tables 1 and 2 . The Chartis assessment outcomes were the following in the 321 patients of the efficacy population: 265 patients were $\mathrm{CV}$ negative, 46 were rated 'inconclusive', 4 were CV positive, 4 'not done', and there were 2 patients with missing data.

\section{Efficacy Outcomes}

The mean changes between baseline and the 6-month follow-up visit are presented in table 3 . With respect to lung function test parameters, the mean $\mathrm{FEV}_{1}$ increase was $100 \mathrm{ml}$, a change of $+11.9 \%$, reaching the usual minimal clinically important difference (MCID) for this parameter $(+100 \mathrm{ml})$ [24]; correspondingly, residual vol- 
Table 3. Changes in lung function tests and questionnaires between baseline and 6 months

\begin{tabular}{|c|c|c|c|}
\hline & \multicolumn{3}{|l|}{ Visits } \\
\hline & baseline & 6 months & $\mathrm{p}$ value \\
\hline \multicolumn{4}{|l|}{$\mathrm{FEV}_{1}, \mathrm{l}(\mathrm{n}=307)$} \\
\hline Value $(95 \% \mathrm{CI})$ & $0.85(0.82,0.88)$ & $0.95(0.90,1.00)$ & \\
\hline \% change (95\% CI of the mean) & - & $+11.9(8.74,15.11)$ & $<0.0001$ \\
\hline \multicolumn{4}{|l|}{$\mathrm{RV}, \mathrm{l}(\mathrm{n}=304)$} \\
\hline Value $(95 \% \mathrm{CI})$ & $5.70(5.55,5.84)$ & $5.27(5.10,5.44)$ & \\
\hline Change (95\% CI of the mean) & - & $-0.42(-0.56,-0.29)$ & $<0.0001$ \\
\hline \multicolumn{4}{|l|}{ FVC, $1(n=303)$} \\
\hline Value $(95 \% \mathrm{CI})$ & $1.96(1.87,2.04)$ & $2.11(2.03,2.19)$ & \\
\hline \% change ( $95 \%$ CI of the mean) & - & $+12.15(8.70,15.60)$ & $<0.0001$ \\
\hline \multicolumn{4}{|l|}{ mMRC score, points $(n=303)$} \\
\hline Value $(95 \% \mathrm{CI})$ & $3.00(2.90,3.09)$ & $2.50(2.39,2.62)$ & \\
\hline Change (95\% CI of the mean) & - & $-0.49(-0.62,-0.37)$ & $<0.0001$ \\
\hline \multicolumn{4}{|l|}{ CAT score, points $(\mathrm{n}=283)$} \\
\hline Value $(95 \% \mathrm{CI})$ & $24.49(23.71,25.28)$ & $21.36(20.47,22.24)$ & \\
\hline Change ( $95 \%$ CI of the mean) & - & $-3.14(-3.93,-2.34)$ & $<0.0001$ \\
\hline
\end{tabular}

MCID for RV: -0.31 to -0.43 liter; MCID for mMRC: -1 point; MCID for CAT: -2 points. FVC $=$ Forced vital capacity.

ume (RV) decreased by -0.42 liter, close to the highest value for the respective MCID ( -0.31 to -0.43 ) [25]. The CAT score decreased by -3.14 points between baseline and 6 months, above the MCID for this health-related questionnaire for COPD patients ( -2 points) [26].

\section{Safety Outcomes}

The 'treatment period' corresponds to the initial hospital stay for ELVR with Zephyr ${ }^{\circledR}$ valves. The mean duration of this stay was 7.5 days (2-65). At the time of data extraction, 498 patients were treated with Zephyr ${ }^{\circledR}$ valves. Among them, 5 patients died before hospital discharge: (1) 1 case of severe hypoxia with secondary cardiac dysrhythmia, (2) 1 case of pulmonary thromboembolism, (3) 1 case of ventilation insufficiency with subsequent septic multiorgan failure, (4) 1 case of acute respiratory distress syndrome, and (5) 1 case of severe sepsis. Two deaths were related to the preprocedure patient condition $(2,3)$, and three were rated 'procedure-related' $(1,4,5)$. Additionally, among the 498 treated patients, 70 experienced during hospitalization at least one SAE and 16 one AE, with a total number of patients with AEs/SAEs of 86 (17.2\%). In this population, there was a total of $107 \mathrm{AEs}$, 87 of them being SAEs. A total of 55 cases of pneumothorax, 7 COPD exacerbations, 7 cases of hypoxia, 5 pneumonia, and 5 cases of valve migration were recorded by the investigators.
Table 4. Relationships between AEs and Zephyr ${ }^{\circledR}$ EBV and/or ELVR procedure

\begin{tabular}{lll}
\hline & $\begin{array}{l}\text { Relationships with } \\
\text { EBV }\end{array}$ & $\begin{array}{l}\text { Relationships with } \\
\text { ELVR procedure }\end{array}$ \\
\hline Related & $17(25.8)$ & $45(68.2)$ \\
Not related & $38(57.6)$ & $16(24.2)$ \\
Unknown & $11(16.7)$ & $5(7.6)$ \\
\hline Total AEs & $66(100)$ & $66(100)$ \\
\hline
\end{tabular}

Data indicate number of events (\% of events).

Among the 343 patients who were included in the safety population, $55(16 \%)$ experienced a total of 66 AEs. The opinions of the treating physicians regarding the relationship between the event and the EBV and/or ELVR procedure were sought and are presented in table 4 . According to the physicians, 17 out of 66 AEs $(25.8 \%)$ were related to the device and 45 out of $66(68.2 \%)$ to the procedure.

Among the 66 AEs, 50 were serious in 43 patients (12.5\%). Thirty-one of the SAEs were related to a pneumothorax, which is an expected complication of the procedure that reflects the rapid change in lung volume. No death was recorded over the days following procedure in the safety population. The AEs and SAEs collected during the treatment period are summarized in table 5. In this 
Table 5. Number of AEs and SAEs during treatment period

\begin{tabular}{lcccc}
\hline Type of event & $\begin{array}{c}\text { AEs }+ \\
\text { SAEs }\end{array}$ & AEs & SAEs & $\%^{\mathrm{a}}$ \\
\hline Death & 0 & - & - & 0 \\
Pneumothorax & 35 & 4 & 31 & 10.2 \\
COPD exacerbation & 5 & 3 & 2 & 1.5 \\
Pneumonia (1 distal to valve) & 4 & - & 4 & 1.5 \\
Hypoxia & 4 & 1 & 3 & 1.2 \\
Valve migration & 3 & 2 & 1 & 0.8 \\
Fistula & 2 & - & 2 & 0.5 \\
Pleural effusion & 2 & 1 & 1 & 0.5 \\
Respiratory failure & 1 & - & 1 & 0.29 \\
Mild hemoptysis & 1 & 1 & - & 0.29 \\
Pleuritis & 1 & - & 1 & 0.29 \\
Increased sputum & 1 & 1 & - & 0.29 \\
Other & 7 & 3 & 4 & 2.0 \\
\hline Total & 66 & 16 & 50 & \\
\hline
\end{tabular}

${ }^{a}$ Number of events/number of patients in the safety population $(\mathrm{n}=343)$.

table, the seven 'other AEs' are: hypertensive crisis, gastric ulcer bleeding, fever, sinus tachycardia, candida laryngitis, decline in physical capacity, and prolongation of hospitalization due to back pain.

In all 35 cases with pneumothorax, the occurrence was within the first week after EBV therapy. Pneumothorax was observed the day of the ELVR procedure in 21 cases (60\%), the following day in 8 cases (23\%), between day 2 and day 4 in 5 cases (14\%), and at day 6 in 1 patient. The hospital stay was prolonged in 30 out of 35 cases of pneumothorax, from 1 day to 27 days. In 25 cases, the hospitalization was prolonged for a maximum of 15 days. Pneumothorax resolved spontaneously in 8 cases (23\%) and, in 27 cases, a chest drain with or without suction was needed to alleviate the condition. A single valve was removed in 10 cases, and 1 patient required the removal of all valves. A surgical intervention was further indicated in only 3 cases $(8.6 \%)$.

The 'follow-up period' corresponds to the time period between the hospital discharge and the 6-month followup visit. Among the 343 patients who have been treated with Zephyr ${ }^{\circledR}$ valves and followed-up to 6 months, 127 (37\%) experienced a total of 175 AEs. Among the 175 AEs, 170 were serious in 125 patients $(36.4 \%)$. Ninety (53\%) of the SAEs were related to a COPD exacerbation. No death was recorded in the safety population over the 6 months of follow-up. The AEs and SAEs collected during the 'follow-up period' are summarized in table 6 . In this table, the 9 'other SAEs' are: rehabilitation at hospital (2), increasing dyspnea, pharynx carcinoma, cardiac failure, lower leg swellings and thoracic pain, osteoporotic pain syndrome, check-up for lung transplantation, and increased sputum.

\section{Discussion}

\section{Efficacy Outcomes of ELVR with the Zephyr ${ }^{\circledR} E B V$}

Clinically meaningful and statistically significant $(\mathrm{p}<$ 0.0001 ) improvements in the major outcome variables are shown in the interim results of this observational study, especially with respect to $\mathrm{FEV}_{1}(+100 \mathrm{ml},+11.9 \%)$, $\mathrm{RV}$, and CAT score, where the usual MCIDs are reached. With respect to $\mathrm{FEV}_{1}$, it is known that a change in trough $\mathrm{FEV}_{1}$ of about $100 \mathrm{ml}$ can be perceived by patients, and correlates with fewer relapses following exacerbations [25].

The results of the LIVE Study are better than those reported by Sciurba et al. [7] and by Herth et al. [8] for the US VENT and Euro-VENT, respectively. These better outcomes are not explained by the severity profile of the treated patients, as $\mathrm{FEV}_{1}$ and $\mathrm{RV}$ in \% predicted are similar in both study populations. In both VENT cohorts, high-resolution computed tomography was retrospectively used to identify a complete interlobar fissure indicating the absence of interlobar CV. Therefore, the explanation is probably the use in LIVE of the Chartis Pulmonary Assessment System which provides an accurate and effective detection of interlobar $\mathrm{CV}$ and helps physicians determine the best lobes(s) for valve implantation, thus leading to lobar occlusion and subsequent relevant clinical benefits. Although the effect on $\mathrm{FEV}_{1}$ in two recent RCTs, STELVIO [12] (140 ml, $+17.8 \%$ after 6 months) and BeLieVeR HIFi [11] (160 ml, $+20.9 \%$ after 3 months) are more pronounced, the present results from the LIVE observational study appear to both demonstrate the diagnostic value of Chartis and confirm, in a real-world population, the clinical effectiveness of EBV therapy matching or exceeding the results from more selective RCTs using competitive technologies. Of note, some patients treated in the LIVE Study had either unknown or even positive CV status (fig. 1).

\section{Safety Profile of the Zephyr ${ }^{\circledR} E B V$}

In this interim analysis, a total of 343 emphysema patients have currently been treated with Zephyr ${ }^{\circledR}$ valves and followed up to 6 months. During the treatment period, 55 patients (16\%) experienced a total of 66 AEs/ 
Table 6. Number of AEs and SAEs during follow-up

\begin{tabular}{|c|c|c|c|c|c|}
\hline Type of event & $\mathrm{AEs}+$ SAEs & AEs & SAEs & Missing & $\%^{\mathrm{a}}$ \\
\hline Death & 0 & - & - & - & 0 \\
\hline COPD exacerbation & 93 & 2 & 90 & 1 & 27.1 \\
\hline Pneumonia (1 distal to valve) & 22 & - & 22 & - & 6.4 \\
\hline Bronchitis/infection/pleuritis & 4 & - & 4 & & 1.2 \\
\hline Pneumothorax & 7 & - & 7 & - & 2.0 \\
\hline Respiratory failure & 4 & - & 4 & - & 1.2 \\
\hline Hemoptysis & 2 & - & 2 & - & 0.6 \\
\hline Valve migration & 6 & - & 6 & - & 1.7 \\
\hline Valve removal & 4 & - & 4 & - & 1.2 \\
\hline Additional valve implantation & 10 & - & 10 & - & 2.9 \\
\hline Valve re-implantation & 4 & - & 4 & - & 1.2 \\
\hline EBV control ${ }^{b}$ & 7 & - & 7 & - & 2 \\
\hline Other & 10 & - & 9 & 1 & 2.9 \\
\hline Unknown & 2 & - & 1 & 1 & 0.6 \\
\hline Total & 175 & 2 & 170 & 3 & \\
\hline
\end{tabular}

${ }^{a}$ Number of events/number of patients in the safety population $(n=343) .{ }^{b}$ Bronchoscopy performed to check the position of the valve(s).

SAEs. These included 35 cases of pneumothorax ( 31 were SAEs), 5 COPD exacerbations, 4 cases of pneumonia, 4 cases of hypoxia, 3 cases of valve migration, 2 fistulas, 2 pleural effusions, 1 mild hemoptysis and 1 case of respiratory failure. During the 6-month subsequent follow-up, 170 SAEs were collected in 125 patients (36.4\%). Ninety (53\%) of these SAEs were COPD exacerbations, a common complication in severe to very severe COPD patients. There were also 22 cases of pneumonia. All these complications are proactively monitored by TCs to ensure patient safety. No deaths were recorded in the safety population of this analysis.

These safety data collected in a routine end-stage COPD population are consistent with the data reported in clinical trials by Sciurba et al. [7] and Herth et al. [8, 9], and confirm the safety profile of the Zephyr ${ }^{\circledR}$ valves in emphysema patients treated in daily practice. In the VENT Study publication from Sciurba et al. [7], the most common AE in the EBV group were COPD exacerbations requiring hospitalization (7.9\%), hemoptysis (5.6\%), pneumonia and pneumothorax ( $4.2 \%$ for both), and the rates of death were $2.8 \%$ at 6 months and $3.7 \%$ at 12 months. In the European VENT study cohort, Herth et al. [8] reported a total of 42 COPD exacerbations with hospitalization (37.8\%), 14 cases of hemoptysis (12.6\%), 13 cases of pneumonia not distal to valves (11.7\%), 9 pneumothoraces/air leaks (8.1\%), 7 cases of respiratory failure with more than 24-hour ventilation (6.3\%), and 6 deaths
(5.4\%) during the 1-year follow-up of $111 \mathrm{EBV}$ patients. In the most recent publication from Herth et al. [9], 19 among 96 patients treated with EBV (20\%) had experienced a SAE. In those patients, a total of 20 SAEs were reported: 8 cases of pneumothorax, 7 COPD exacerbations, 1 case of pneumonia, dyspnea and respiratory failure, and 2 deaths. Likewise, 23 events in 34 patients were reported in STELVIO [12] by 6 months (death 3\%, COPD exacerbation $12 \%$, pneumonia $6 \%$, pneumothorax $18 \%$ ) and 43 events in 25 patients in BeLieVeR-HIFi [11] (death $8 \%$, exacerbations requiring hospitalization $20 \%$, pneumothorax 8\%).

Our LIVE study has several strengths and limitations. Strengths include the relatively large cohort of prospectively enrolled and consecutive patients with ELVR who were followed for a period of 6 months. The LIVE cohort is the largest of its kind today. Limitation includes the relatively high number of patients lost to follow-up and lack of a control group of patients with emphysema who did not receive ELVR.

In conclusion, the LIVE study is a currently ongoing prospective cohort observational study designed to evaluate the long-term effectiveness and safety of the Zephyr ${ }^{\circledR}$ valves in the treatment of emphysema patients. The preliminary results confirm the effectiveness of the EBV therapy and the efficacy/safety ratio of the Zephyr ${ }^{\circledR}$ valve in a large-scale population treated in the context of reallife daily practice. 


\section{Appendix}

LIVE I: List of 93 Active RCs

RC002: Dr. Sommer, Garmisch-Partenkirchen; RC003: Dr. Obermüller, Germering; RC004: Drs. Rolke and Rückert, Aschaffenburg; RC005: Dr. Bullemer, München; RC006: Dr. Weber, Starnberg; RC007: Drs. Kemmerich and Erbes, München; RC008: Dr. Tzimas, München; RC009: Dr. Weber, Augsburg; RC010: Dr. Bisping-Arnold, Freising; RC011: Dr. Fischer, München; RC012: Dr. Heindl, Gauting; RC013: Dr. Oelker, Weilheim; RC014: Dr. Schlesinger, Bad Oeynhausen; RC015: Dr. Krüll, Berlin; RC0016: Dr. Powitz, München; RC017: Drs. Höffgen, Kestermann, and Kösters, Rheine; RC018: Dr. Mildner, Euskirchen; RC020: Dr. Steffen, Landsberg; RC021: Drs. Grill, Weeg, and Schmidt, München; RC022: Dr. Grimm-Sachs, Bruchsal; RC023: Dr. Frisch, München; RC024: Dr. Bachfischer, Schrobenhausen; RC025: Dr. Steinkirchner, Landshut; RC026: Dr. Jansen, Menden; RC027: Dr. Overlack, Bonn; RC028: Dr. Syriste, Bad Salzufflen; RC029: Dr. Bialodrzewski, Wismar; RC030: Dr. Tobias, Dortmund; RC032: Dr. Korduan, Berlin; RC033: Dr. Vogt, Berlin-Kladow; RC034: Dr. Hübner, Dillingen; RC037: Drs. Stein and Böhlandt, Bad Tölz; RC038: Dr. Bourgeois, Dachau; RC039: Dr. Kemme, Neu Ulm; RC040: Dr. Haase, Halle; RC042: Dr. Kammler-Baumann, München; RC043: Dr. Lohse, Beelitz-Heilstätten; RC044: Dr. Hennig, Radebeul; RC045: Dr. Feurer, München; RC046: Dr. Reiner, Fürstenfeldbruck; RC047: Dr. Schmidt, Koblenz; RC048: Dr. Krugmann, Bietigheim-Bissingen; RC049: Drs. Eberhardt and Welling, Lübeck; RC050: Dr. Seiz, Leonberg; RC053: Dr. Kirchpfening, Nürnberg; RC054: Dr. Schulz, Karlsruhe; RC055: Dr. Pauli, Schwalmstadt; RC056: Dr. Hagedorn, Bocholt; RC058: Dr. Gogoll, Berlin; RC059: Dr. Birkholz, Stade; RC060: Dr. Willwersch, Sonthofen; RC061: Dr. Doepner, Dortmund; RC062: Dr. Hammers-Reinhard, Homburg; RC064: Dr. Dünzel, Niesky; RC065: Dr. Bader, Dresden; RC066: Dr. Reinert, Saarbrücken; RC067: Drs. Graf and Roeff, Freital; RC068: Dr. Franke, Sonnenberg; RC070: Dr. Mühle, Teuchern; RC072: Drs. Schult-Kronefeld and Schönewolf, Norderstedt; RC073: Dr. Kehm, Dortmund; RC074: Drs. Sorgenfrei and Akrivakis, Hamburg; RC075: Dr. Gebhardt, BerlinNeukölln; RC076: Dr. Roggenkamp, Osnabrück; RC077: Dr. Hartung, Lüdenscheid; RC079: Drs. Rüenauver and Seemayer, Wiesbaden; RC080: Drs. Steinmetz and Forster, Darmstadt; RC081: Dr. Dyong, Andernach; RC082: Dr. Feimer, München;
RC084: Dr. Warstat, Berlin; RC086: Dr. Brust, Hellstedt; RC087: Dr. Marschall, Erding; RC088: Dr. Apprich, Worms; RC089: Dr. Markoff, Schorfheide; RC090: Dr. Aries, Hamburg; RC091: Dr. Andreas, Immenhausen; RC092: Dr. van Heiss, Würselen; RC094: Dr. Lafon, Stadthagen; RC095: Dr. Xanthopoulos, Fürstenwalde; RC096: Dr. Thöne, Bonn; RC098: Dr. Köhl, München; RC099: Dr. Gaul, Traunstein; RC100: Dr. Bezler, Aalen; RC102: Dr. Hoffmann, Hannover; RC103: Dr. Chesin, Frankfurt; RC104: Dr. Kampschulte, Berlin; RC107: Dr. Rieder-Nelissen, Darmstadt; RC108: Drs. Feussner and Reinhardt, Kassel; RC109: Dr. John, Schwedt; RC110: Dr. Voss-Dierks, Hannover; RC112: Dr. Krieger, München; RC113: Dr. Werner, Kevelaer; RC114: Dr. Kasper, Grevesmühlen.

\section{Acknowledgements}

List of active TCs (in alphabetical order of investigator name): Balli T. (Lübeck), Baron S. (Würzburg), Behler P.G. (Goch), Benedikter G. (München), Blaas S. (Donaustauf), Born T. (Rüsselsheim), Blankenburg T. (Halle-Saale), Budweiser S. (Rosenheim), Drömann D. (Lübeck), Edelmann M. (Aalen), Eggeling S. (Berlin), Franke C. (Sonneberg), Fertl A. (München), Gesierich W. (Gauting), Glockner J. (Stuttgart), Grah C. (Berlin), Grübener R./ Tasci S. (Linz/Rhein), Grüning W. (Schwerin), Hambrecht S. (Kehl), Hammerl P. (Immenhausen), Heinrichs A./Hünermann C. (Ostercappeln), Herth F. (Principal Investigator/Heidelberg), Herzmann C. (Borstel), Hirche T. (Wiesbaden), Höffken G./Koschel D. (Coswig), Hübner R. (Berlin), Juifs F./Anrtzen C. (Angermünde), Klose H. (Hamburg), Kohlhäufl M. (Gerlingen), Kortsik C. (Mainz), Kropf-Sanchen C./Schumann C. (Ulm), Litwinenko C. (Halle-Saale), Meyer J. (München), Neumeister W. (Koblenz), Petermann C. (Hamburg), Randerath W. (Solingen), Rieder-Nelissen C. (Darmstadt), Schaaf B. (Dortmund), Schäfer H. (Völklingen), Skowasch D. (Bonn), Schönhofer B. (Hannover), Schwaiblmair M. (Augsburg), Schwick B. (Würselen-Bardenberg), Stanzel F. (Hemer), Stier S. (Karlsruhe), Trautmann H. (Bremerhaven), Turkiewicz R. (Minden), Wagner M. (Nürnberg), Wagner U. (Löwenstein), Wege T. (Buende), Worth H. (Fürth).

This study was supported by Pulmonx (Neuchâtel, Switzerland) and GCP-Service International Ltd. \& Co. KG (Bremen, Germany).

\section{References}

1 The American Thoracic Society Standards for the diagnosis and care of patients with chronic obstructive pulmonary disease. Am J Respir Crit Care Med 1995;152:s77-s121.

2 WHO: Noncommunicable diseases. http:// www.who.int/mediacentre/factsheets/fs355/ en/index.htlm.

3 Global Initiative for Chronic Obstructive Lung Disease (GOLD): Global strategy for the diagnosis, management, and prevention of chronic obstructive pulmonary disease (updated 2014). http://goldcopd.org/.

4 National Emphysema Treatment Trial Research Group: A randomised trial comparing lung-volume-reduction surgery with medical therapy for severe emphysema. N Engl J Med 2003:348:2059-2073.

$\checkmark 5$ Criner G, Sternberg AL, National Emphysema Treatment Trial: The major outcomes of lung volume reduction surgery in severe emphysema. Proc Am Thorac Soc 2008;5:393-405.

$\checkmark 6$ Herth FJF, Slebos DJ, Rabe KF, Shah PL: Endoscopic lung volume reduction: an expert panel recommendation. Respiration 2015;91: 241-250.

7 Sciurba FC, Ernst A, Herth FJF, Strange C, Criner G, Marquette $C$, et al: A randomized study of endobronchial valves for advanced emphysema. N Eng J Med 2010;363:12331244.

8 Herth F, Noppen M, Valipour A, Leroy S, Vergnon J-M, Ficker JH, Egan E, Gasparini S, Agusti C, Homes-Higgin D, Ernst A; International VENT Study Group: Efficacy predictors of endoscopic lung volume reduction with Zephyr valves in a European cohort with emphysema. Eur Respir J 2012;39:1334-1342.

-9 Herth FJF, Eberhardt R, Gompelmann D, Ficker JH, Wagner M, Ek L, Schmidt B, Slebos DJ: Radiological and clinical outcomes of using chartis to plan endobronchial valve treatment. Eur Respir J 2013;41:302-308. 
10 Gompelmann D, Eberhardt R, Michaud G, Ernst A, Herth FJ: Predicting atelectasis by assessment of collateral ventilation prior to endobronchial lung volume reduction: a feasibility study. Respiration 2010;80:419-425.

-11 Davey C, Zoumot Z, Jordan S, McNulty WH, Carr DH, Hind MD, Hansell DM, Rubens MB, Banya W, Polkey MI, Shah PL, Hopkinson NS: Bronchoscopic lung volume reduction with endobronchial valves for patients with heterogeneous emphysema and intact interlobar fissures (the BeLieVer-HIFi study): a randomized controlled trial. Lancet 2015; 386:1066-1073

12 Klooster K, Ten Hacken NH, Hartman JE, Kerstjens HA, van Rikxoort EM, Slebos DJ: Endobronchial valves for emphysema without interlobar collateral ventilation. N Engl J Med 2015;373:2325-2335.

$\checkmark 13$ Hopkinson NS, Kemp SV, Toma TP, Hansell DM, Geddes DM, Shah PL, Polkey MI: Atelectasis and survival after bronchoscopic lung volume reduction for COPD. Eur Respir J 2011;37:1346-1351.

14 Venuta F, Anile M, Diso D, Carillo C, De Giacomo T, D'Andrilli A, Fraioli F, Rendina EA, Coloni GF: Long-term follow-up after bronchoscopic lung volume reduction in patients with emphysema. Eur Respir J 2012;39: 1084-1089.
15 Bosc C, Jankowski A, Briault A, Roth H, Reymond E, Arbib F, Federspiel I, Vincent C, Aniwidyaningsih W, Ferretti G, Pison C: Long-term outcomes in 35 patients with emphysema after endoscopic lung volume reduction (ELVR) with valves. Eur Respir J 2014;44(suppl 58):A3734.

16 Oliveira $\mathrm{H}$, Rambo R, Oliveira S, Macedo-Neto A: Two-year follow-up with patients treated with Zephyr valves over 10 years: Focus on safety. Eur Respir J 2014;44(suppl 58):A3713.

17 Park TS, Hong Y, Lee JS, Lee SM, Seo JB, Oh YM, Lee SD, Lee SW: Efficacy of bronchoscopic lung volume reduction by endobronchial valves in patients with heterogeneous emphysema: report on the first Asian cases. Korean Med Sci 2014;29:1404-1410.

18 Hillerdal G, Mindus S: One-to four-year follow-up of endobronchial lung volume reduction in alpha-1-antitrypsin deficiency patients: a case series. Respiration 2014;88:320 328.

19 Iftikhar IH, McGuire FR, Musani AI: Predictors of efficacy for endobronchial valves in bronchoscopic lung volume reduction: a meta-analysis. Chron Respir Dis 2014;11: 237-245.

20 Choi M, Lee WS, Lee M, Jeon K, Sheen S, Jheon S, Kim YS: Effectiveness of bronchoscopic lung volume reduction using unilateral endobronchial valve: a systematic review and meta-analysis. Int J Chron Obstruct Pulmon Dis 2015;10:703-710.
21 Shah PL, Herth FJF: Current status of bronchoscopic lung volume reduction with endobronchial valves. Thorax 2014;69:280-286.

-22 Gompelmann D, Herth FJF, Slebos DJ, Valipour A, Ernst A, Criner GJ, Eberhardt R: Pneumothorax following endobronchial valve therapy and its impact on clinical outcomes in severe emphysema. Respiration 2014;87:485-491.

23 Valipour A, Slebos DJ, de Oliveira HG, Eberhardt R, Freitag L, Criner GJ, Herth FJ: Expert statement: pneumothorax associated with endoscopic valve therapy for emphysema - potential mechanisms, treatment algorithm, and case examples. Respiration 2014;87:513-521.

24 Donohue JF: Minimal clinically important differences in COPD lung function. COPD 2005;2:111-124.

25 Hartman JE, ten Hacken NHT, Klooster K, Boezen HM, de Greef MHG, Slebos DJ: The minimal important difference for residual volume in patients with severe emphysema. Eur Respir J 2012;40:1137-1141.

26 Kon SSC, Canavan JL, Jones SE, Nolan CM, Clark AL, Dickson MJ, et al: Minimum clinically important difference for the COPD Assessment Test: a prospective analysis. Lancet Respir Med 2014;2:195-203. 